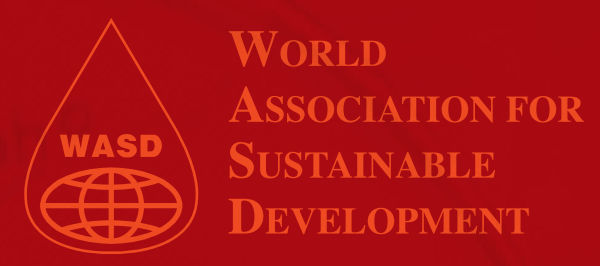

Hussam Hamrawi ${ }^{1}$ University of Bahri, Sudan

\title{
Design and implementation of computer science curriculum in extreme conditions: First results
}


Design and implementation of computer science curriculum in extreme conditions: First results 


\section{Abstract}

Purpose This study reports the first results of the design and implementation of a computing curriculum in its third year in conditions that we believe to be extreme. Such conditions may arise in countries that suffer from conflicts or civil war.

Methodology The study has been carried out from actual events and data from published and official documents.

Findings The first results have been statistically analysed and show positive transformation of many computer illiterate students into computer programmers, given extremely limited resources.

\section{Research limitations/}

implications The study has been carried out in the specific case of the University of Bahri, a university born out of the secession of the Republic of South Sudan from the Republic of Sudan. The study reports three years of implementation, so further research should be carried out after graduation of the first batch of students.
Practical implications The study contributes to the understanding of extreme conditions in university education that face least developed countries in general and those affected by conflict in particular. It also contributes to the design and implementation plan of a computer science curriculum.

Originality/value To the best of the author's knowledge, no such study exists. The study reports first results that enable similar research to be conducted and will hopefully instigate active debate among researchers.

Keywords Computing curriculum, Computer science curriculum, Curriculum design 


\section{Introduction and background}

In July 2011, The Republic of South Sudan (hereafter referred to as South Sudan) seceded from The Republic of Sudan (hereafter referred to as Sudan) and new conditions faced and continue to face both countries (Christopher, 2011). Living situations in Sudan became and still are extremely difficult due to a severe economic downturn (Mohamed, 2011). These factors, i.e. the secession and the economy, form what I define as extreme conditions. These extreme conditions can be summarised by the following:

\section{- Lack of time for restructuring and commencing study}

- Administrative staff not familiar with many confusing decisions after secession

- Senior year students from the University of Juba not familiar with the new situation, causing some unrest throughout the university - Lack of qualified instructors (PhD
holders)

\section{- Lack of infrastructure (laboratories)}

These conditions shall be discussed in detail in the following section. How to cope with these conditions across the University of Bahri (hereafter referred to as Bahri) in general and within the college of computer sciences in particular, is the subject of another research paper. The purpose of this study is to report the first results of designing and implementing the computer science curriculum.

Many design considerations became apparent due to the above-mentioned factors. The researcher will mainly concentrate on the bachelor of computer science programme and show the progress of students studying under this programme from their admission until their third year of study under such extreme conditions. I strongly believe this study will instigate related research in countries suffering similar conditions. In this paper, the challenges affecting the design and implementation of the curriculum will be the first topic of discussion. The design considerations and implementation strategy will then follow. The first results will then be presented, followed by the concluding remarks.

\section{Challenges}

The main challenges that affect the design considerations of the curriculum come from two different, but related factors.

Firstly, the University of Bahri is a new university formed after the secession of South Sudan and it constitutes four universities, namely Juba, Baher-elGazal, Upper Nile and Rumbek universities (University of Bahri, 2014). These universities used to be national Sudanese universities in which two-thirds of their staff and students were from Sudan and only a third from South Sudan. These universities were dislocated for some considerable time in 
Khartoum, the Sudanese capital. The main aim of the formation of the University of Bahri is to relocate the staff and students of the four universities. Moreover, the number of students sitting for national secondary examinations is rising steadily, which means that student intake must not be decreased at any cost. This extraordinary situation meant that the staff and students of the four universities had to be exposed to a very new and confusing environment, and cope with very new and confusing decisions.

Let us consider one of the main decisions that caused wide unrest throughout the university. The university was faced by the presence of students from the same programme and level, but different universities studying varied curricula. Such students had to study in the same class and have their curriculum varied in such a way that they satisfied the requirements of the degree. A committee for solving such conflicting situations had to carry out extensive studies on a tight schedule.

Another decision that caused unrest throughout the university was the decision that all the Sudanese students of the four southern universities should be transferred to the University of Bahri regardless of their level of study, and should be given their final certificates from the University of Bahri. This situation was unprecedented, and was the result of failure of negotiations between the two ministries of higher education in Sudan and South Sudan affected by the political tensions after secession. Although an agreement between the former four universities and the University of Bahri was reached, it could not be implemented at the time. This situation caused many students to be confused, especially students in the later years of their study. Many of them actually made demonstrations and caused the new university to close down for some time.

As a consequence of these issues, decisions had to be made in a timely manner and in the interests of the students. Curricula had to be modified and updated in one month, so that students would not be affected and their time not wasted. This is the first extreme condition which affected the design considerations and implementation of curricula.

The second challenge was the severe economic conditions that Sudan was and is still facing. The forecast at the time was that the economic downturn would affect the country for some time. By the end of 2011 the exchange rate of the currency against the US Dollar was rising significantly and doubled by 2012 and tripled by 2013. Prices kept rising and reached $100 \%$ by 2012 , a record high in 2013 and the officially announced inflation rate reached $28 \%$ in 2013 (Elbeely, 2013). This extreme condition was facing all sectors of the society and business community. It caused many university instructors, especially in computing disciplines, to seek work abroad. The numbers of fleeing university professors was staggering, and the National Assembly, i.e. the parliament, called for a special session to discuss the issue (Sudan Tribune, 2013). The Ministry of Finance was actually in favour of this massive brain export that would help the economy, but at the same time left universities suffering drought in human resources with increasing numbers of students seeking higher education. This extreme condition left the college of computer sciences without enough human resources and without facilities. There were at the time one assistant professor, three lecturers, two teaching assistants, five technicians and five administrative staff. There were also three lecture halls with a full capacity of 270 students, and two computer 
laboratories with a full capacity of fifty students. In addition, there were two bachelor programmes that include six students in the third year, six in the second year and eighty-five in the first year. Moreover, there were three technical diploma programmes with thirty-five students in the third year, fourteen in the second year and ten in the first year. There were also two postgraduate programmes with twenty students. The situation was also affected by the relocation of the university headquarters in the computer studies building. This left the building in need of renovation and thus the need of extra funds.

The lack of academic staff in general and staff from the computing profession in particular was also affected by three factors. First, the nearby Kingdom of Saudi Arabia implemented a new higher education strategy that allowed it to open several new universities and Sudanese staff members were favoured for their long association with Saudi education. Second, the nearby State of Libya also decided to open several universities with wages almost ten times that of Sudan. Third, the local business sectors, such as the telecommunication and petroleum sectors, attract most of the talented graduates. This left the computing profession as whole under extreme pressure to cope with the situation and left the college of computer sciences under extreme conditions.

These extreme conditions heavily affect the design considerations and the implementation strategy of the curricula of the college of computer sciences. In addition, computing being relatively new, unlike engineering or other sciences, the number of graduates qualified to work as academic staff is considerably less than those in other disciplines. As part of the expansion strategy implemented in the college, an advertised job for PhD-holders in computing or a related specialisation was announced for more than three months and not a single applicant was found. Therefore the college had to rely on master's degree-holders to teach, which became a trend in the last few years in Sudanese universities.

Another consideration was that even those lecturers had to be attracted by providing them with time to work in other businesses beside their work in the university. This meant that such lecturers would only be available for certain lectures. The curricula design and implementation should incorporate such situations too.

Some might argue that in such conditions the learning environment does not permit such programmes to exist. In response to such arguments, the college surveyed other Sudanese colleges and found that slightly better situations are found in the University of Khartoum (UofK), Sudan University for Science and Technology (SUST), Alnilien University (Alnilien), and Alzaim Alazhary University (Alazhary). On the other hand, many of the other government universities are found to have similar situations and those in universities outside Khartoum are considering dissolving these programmes. In private universities, better situations are found and some even recruit staff from countries in South East Asia. The college also consulted the data from the Ministry of Higher Education, showing that there is a steady $5 \%$ increase in students willing to study computing programmes. As a result, the college decided to pursue computing education and design a curriculum that considers these extreme conditions and implement a strategy that maintains reasonable quality and results in a successful programme with such limited resources. 
In the following section, the design considerations and implementation strategy are explained.

\section{Curriculum design and implementation}

In this section I will explain the main points of the conceptual framework of the college of computer sciences and introduce the structure of the curricula (see Figure 1) used in the college and what I call the "minimum quality assurance measures" (MQAM) used to govern the learning process for the extreme conditions mentioned earlier.

Figure 1. The structure of the curricula of the college of computer sciences

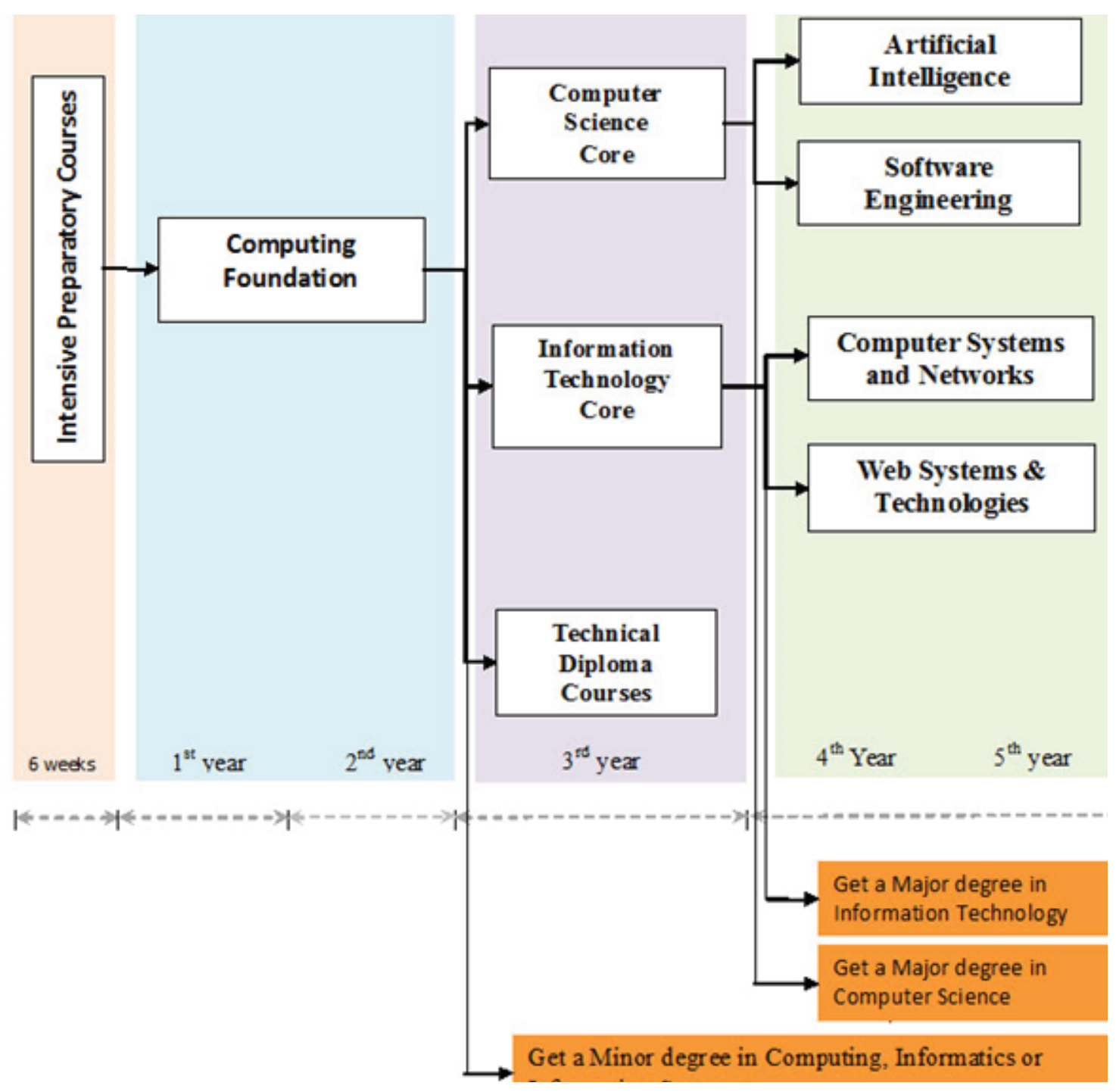


First of all the college considered a very ambitious plan of progress which was present in its conceptual framework. The vision of the college is "the perfection and excellence in teaching, research and community service in the fields of computer sciences". Its mission is "to provide quality education and excellent research in order to qualify competent cadres in the various fields of computer sciences". Its objectives are:

- Assurance of quality and excellence in education

- Production of high quality and original scientific research

- Playing an effective and noticeable role in the service of the local community

- Delivery of academic and technical services with a high level of perfection and professionalism

- Enrichment of the current job market with competent cadres

- Contribution in the making of future job markets

- Gaining accreditation from national, regional and international respected bodies

In order to fulfil this framework the college had to progress steadily through a plan of action that included a curriculum design that had to cope with the current situation and still be able to fulfil international computing curriculum standards.
The following design choices have been made:

1. Ten semesters given in five years of study towards a bachelor of science honours degree

2. Three stages based on requirements i.e. college, department and specialisation

\section{Six computing elective courses}

\section{Four general elective courses}

\section{Eighteen credit hours allocated for projects}

The first choice is a general theme across the University of Bahri which offers honours degrees in five years and each academic year is divided into two semesters. The three stages in the second choice is derived by the need to introduce common courses for as many courses as possible across the college. The few members of staff across the college required this feature, and keeping the design of the curriculum simple to implement meant that the structure of all curricula had to be the same across programmes. The first stage constitutes the university requirement semester, and three foundation semesters. These semesters include introductory topics to programming, mathematics, hardware and software structures, databases, and networking. The topics cover most of the core knowledge areas identified by the IEEE/ACM curriculum standards (Sahami, 2014).

The second stage covers most of the departmental requirement courses in three semesters. For the computer science curriculum, this stage is covered in two semesters. Topics include core and elective knowledge areas of algorithms and complexity, networking, mathematics and programming. It also covers elective knowledge areas that formulate the introduction to 
specialisations such as artificial intelligence, computer and network security, modelling and software engineering. It also introduces the students to analysis, research and projects. The main objective of this stage is to strengthen students' abilities to use basic computer science tools in problem solving, analysis and application.

The third stage covers some elective knowledge areas of departmental requirements and specialisation requirements. This stage is covered in four semesters and is defined by many elective courses (modules), both general and computing. The choice of elective courses is flexible and based on the availability of staff and resources. The stage is highly affected by the extreme conditions mentioned earlier. The specialisations are affected by the lack of qualified staff (PhD-holders) and many cooperating staff from other universities participate in teaching and supervision. This, off course, makes the determination of specialisation very difficult and could not be planned. In this case, the students are given the degree without specialisation, at least at the current time and the years ahead. At the same time, the curriculum offers the possibility for specialisations to be formulated as staff become available. Some skills, such as project management, job searching and preparation for employment are given considerable attention, along with special emphasis in going through the project lifecycle. The graduation project plays a pivotal role in the degree as it constitutes $8.8 \%$ of the total credit hours of the degree and $12.5 \%$ of the credit hours used for degree classification, i.e. first class, second upper or lower, or third. Such emphasis cannot be found in any of the Sudanese universities. This choice is derived out of job market requirement analysis carried out by the department of computer science. It has to be mentioned that the college curriculum is highly geared towards satisfying the objectives of the college, with a more practical and technical approach.

The implementation of the curriculum also takes into consideration the extreme conditions mentioned earlier. The main implementation plan can be summarised as follows:

\section{Recruiting lecturers with professional experience}

\section{Recruiting lecturers from universities outside of Khartoum}

\section{Allowing lecturers to work in a semi- part-time (SPT) manner}

\section{Applying MQAM}

\section{Reviewing the plan each year}

To explain, the first step of implementation included finding instructors equipped with at least a master's degree and satisfying the higher education employment rule and regulations. This has been done in two ways: first, recruiting new master's degree-holders with professional experience, and this resulted in recruiting four new instructors. Second, recruiting already-employed staff members from universities outside of Khartoum who are willing to move to the capital in pursuit of extra part-time working hours in the industry besides working in the university. In order to fulfil these two steps, the college had to employ a flexible working schedule for its instructors and advertise such policy informally.

The second step was to make sure the quality of education delivered satisfied the standards set out by the College Board and at the same time satisfied the students, as they are the main source of information for the new intake. Minimum quality assurance 
measures have been set out. These include and are not limited to the following:

\section{- Teaching load limitation policy}

- Office hours availability policy

- Practical instruction policy

-The college of computer sciences teaching best practices

The review of the plan outcomes is an integral part of the implementation strategy and it also forms the basis for this paper.

Next we look at the first results reported after three years of implementation.

\section{First results}

First we explain the performance measures considered in this study. Students at admission are asked to fill in a survey through which the levels of English and computer skills are ascertained. Another performance measure is the student intake minimum admitted result from secondary schools. This is a well-rooted measure in cross-university ranking. Another performance measure is somewhat subjective, as college instructors are surveyed about their level of satisfaction with the students' abilities so far.

More than $30 \%$ of the students of the college in the 2011-2012 admission answered that they had not used a computer before. More than 35\% answered that they had not used Microsoft Word or its equivalent. More than $40 \%$ answered that they had not used the internet. More than $85 \%$ did not know what programming was and more than $95 \%$ had not seen a programming language before.

It has to be mentioned that the 20112012 batch of students have been admitted with a maximum result of $68 \%$, whereas their counterparts in other universities are as follows: University of Khartoum: $85 \%$; Sudan University of Science and Technology: 80\%; Alnilien University: 75\%; and Alzaim Alazharay University: 73\%. This can be seen in Table 1, and Table 2 shows the number of students admitted to the college throughout these three years. (For the staffing structure and numbers, see Table 3 )

Table 1. Maximum results of student admission

\begin{tabular}{|cccccc|}
\hline Year & Bahri & UofK & SUST & Alnilien & Alazhary \\
\hline 2011 & 68 & 85 & 80 & 75 & 73 \\
\hline 2012 & 73 & 86 & 80 & 76 & 74 \\
\hline 2013 & 77 & 86 & 81 & 77 & 74 \\
\hline
\end{tabular}


Table 2. Number of students

\begin{tabular}{|ccc|}
\hline Year & Admitted students & Total students \\
\hline 2011 & 80 & 100 \\
\hline 2012 & 100 & 175 \\
\hline 2013 & 100 & 250 \\
\hline
\end{tabular}

Table 3. Number of full-time academic staff in the college

\begin{tabular}{|cccc|}
\hline Year & $\begin{array}{c}\text { Assistant } \\
\text { professors }\end{array}$ & Lecturers & Total \\
\hline 2011 & 1 & 3 & 4 \\
\hline 2012 & 3 & 7 & 10 \\
\hline 2013 & 5 & 11 & 16 \\
\hline
\end{tabular}

Let us now look at what has happened to that batch after three years of studying in the college of computer sciences. Those third year students still have two years to graduate. Some of the indicators of their progress are represented by the quality of their projects and engagement in different programming events, exhibitions and competitions. All students from that batch are members in a programming club they have formed. A team from the club participated in a university-wide event with a mobile application, and several java desktop applications.

This shows that the students are quite confident with programming.

Another measure of how the college is performing at a national level can be seen from the national admission results, which are shown in Table 1.

These results show a significant increase in the quality of student intake, which reflects the increase in the college reputation amongst students.

Another measure of the quality is a survey carried out by the department asking academic staff members for their opinions on the outcome of teaching so far. The result has been a staggering $100 \%$ satisfaction with the progress that the students made. About 30\% considered that the students could have been better.

Although these results are somewhat subjective, they still give a positive indication of the quality of the outcome of the design and implementation of the computer science curriculum under study. 


\section{Summary and conclusion}

In this study we defined what we consider to be extreme conditions that affect the design and implementation of the computer science curriculum of the college of computer sciences, University of Bahri. We discussed the challenges and the design considerations of the curriculum. We also showed the implementation plan of the curriculum. The first results have been discussed.

In conclusion, we believe that the first results show that the design considerations and implementation plan of the curriculum are relatively suitable given the extreme conditions mentioned earlier. The students who were relatively computer illiterate are currently confident programmers.

For future work, more extensive studies will be carried out on the following two batches in the same third year. A regular cross-country programming completion is planned, which will provide a comparative platform between students from different universities. The programming club is planning to enter the IEEE extreme programming competition, which will provide an international comparative platform.
The next checkpoint for this batch will be after their graduation. The department is planning to make an extensive study of the outcome of the five-year programme in cooperation with the UNESCO and a proposal is under preparation for submission.

Finally, it is hoped that this study will instigate research on curriculum design and implementation across the African continent and wherever such extreme conditions are present. Sharing of knowledge and experience may lead to more optimised use of resources in order to compensate for the shortage of these resources. 


\section{References}

Christopher, A.J. (2011) Secession and South Sudan: an African precedent for the future? South African Geographical Journal, 93(2), pp. 125-132.

Elbeely, K. H. (2013) The Economic Impact of Southern Sudan Secession. International Journal of Business and Social Research, 3(7), pp. 78-83.

Mohamed, I. A. (2011) Economic Crisis, Macroeconomic Policies and External Trade in Sudan. Macroeconomic Policies and External Trade in Sudan (October 4, 2011).

Sahami, M. (2014) Computer science curricula for the coming decade. Journal of Computing Sciences in Colleges, 29(6), pp. 7-8.

Sudan Tribune (2013) Sudan concerned about increasing brain drain. Retrieved from: <http://www.sudantribune.com/spip.php?article46423>. [25 March 2014].

University of Bahri (2014) Historical Background. Retrieved from: <http:// bahri.edu.sd/index.php/en/historical-background>. [25 March 2014]. 


\section{About the authors}

Dr. Hussam Hamrawi received his BSc and MSc in Computer Engineering from Girne American University and Near East University in 2000 and 2003, respectively. He also received his $\mathrm{PhD}$ in Computer Science from the Centre for Computational Intelligence at De Montford University, United Kingdom in 2011. Currently, he is a full-time Assistant Professor of Computational Intelligence and Robotics at the University of Bahri, Sudan. He has also been the Dean of the College of Computer Sciences in the University of Bahri since 2011. Dr Hamrawi teaches several computing modules and conducts research on Fuzzy Logic, Uncertainty Modelling and Parallel Computing. 